\title{
Induced radioisotopes in a linac treatment hall
}

\author{
Héctor René Vega-Carrillo a,*, Héctor Asael de Leon-Martinez ${ }^{\mathrm{a}, \mathrm{b}}$, Esteban Rivera-Perez ${ }^{\mathrm{a}}$, \\ Jorge Luis Benites-Rengifo ${ }^{c}$, Eduardo Gallego ${ }^{\mathrm{d}}$, Alfredo Lorente ${ }^{\mathrm{d}}$ \\ a Unidad Académica de Estudios Nucleares de la Universidad Autonoma de Zacatecas, C. Cipres 10, Fracc. La Peñuela, 98060 Zacatecas, Zacatecas, Mexico \\ ${ }^{b}$ Instituto Tecnológico de Aguascalientes, Av. Adolfo López Mateos \#1801 Ote. Fracc. Bona Gens., 20255 Aguascalientes, Mexico \\ 'Centro de Cancerologia de Nayarit, Calzada de la Cruz 118 Sur, 63000 Tepic, Nayarit, Mexico \\ ${ }^{\mathrm{d}}$ Departamento de Ingeniería Nuclear de la Universidad Politécnica de Madrid, C. José Gutiérrez Abascal 2, 28006 Madrid, Spain
}

\section{H I G H L I G H T S}

- Portland cement samples were located inside a treatment hall with a 15 MV linac.

- Induced radioisotopes were measured with a $\mathrm{NaI}(\mathrm{Tl}) \gamma$-ray spectrometer.

- ${ }^{56} \mathrm{Mn},{ }^{24} \mathrm{Na}$, and ${ }^{28} \mathrm{Al}$ were identified and the specific activity was estimated.

- In a wedge, ${ }^{56} \mathrm{Mn}$ was induced by the photoneutrons.

Keywords:

Linac

Neutron

Activation

Gamma-rays

\begin{abstract}
A B S T R A C T
When linacs operate above $8 \mathrm{MV}$ an undesirable neutron field is produced whose spectrum has three main components: the direct spectrum due to those neutrons leaking out from the linac head, the scattered spectrum due to neutrons produced in the head that collides with the nuclei in the head losing energy and the third spectrum due to room-return effect. The third category of spectrum has mainly epithermal and thermal neutrons being constant at any location in the treatment hall. These neutrons induce activation in the linac components, the concrete walls and in the patient body. Here the induced radioisotopes have been identified in concrete samples located in the hall and in one of the wedges. The identification has been carried out using a gamma-ray spectrometer.
\end{abstract}

\section{Introduction}

Up to now more than two hundred types of cancer have been identified and are treated by different methods depending on the lesion type and its progression (Lenox, 2001; Vega-Carrillo et al., 2010). The common treatment includes surgery, radiotherapy and chemotherapy. The radiotherapy is used as teletherapy or brachytherapy, with electrons, photons (X or $\gamma$ ), neutrons, protons, and heavy ions (Amaldi and Braccini, 2011; Agosteo, 2010; Agosteo et al., 1998). These particles deliver a radiation dose in the tumor; seeking none or the lowest dose in the healthy tissues (VegaCarrillo et al., 2010; Zabihzadeh et al., 2009; Ognaro et al., 2000; Price et al., 1978).

The X-ray or electron therapeutic beams are produced in linear

\footnotetext{
* Correspondence to: UaEN-UAZ, C. Cipres 10. Fracc. La Peñuela, 98068 Zacatecas, Zacatecas, México.

E-mail address: fermineutron@yahoo.com (H.R. Vega-Carrillo).
}

accelerators (linacs) that produce neutrons when the accelerator works with voltages larger than $8 \mathrm{MV}$, exposing the patient to a non-negligible dose (Barquero et al., 2005; Kry et al., 2007). This problem is also present in the Hadrontherapy machines (Amaldi and Braccini, 2011; Agosteo, 2010; Agosteo et al., 1998).

It has been pointed out that the low doses received during treatment are the probable cause of the recurrence or the induction of secondary tumors (Travis et al., 2012; Suit et al., 2007). The low dose includes the scattered photons, the induced neutrons, and the photons (prompt and delayed) induced by neutrons (Stathakis et al., 2007; Agosteo et al., 1998).

At any point inside the treatment hall the neutron spectrum, $\Phi_{\mathrm{E}}(E)$, is due to direct neutrons, $\Phi_{\mathrm{E}}(E)_{\mathrm{dir}}$, leaking out from the head of the linac, the neutrons scattered out from the head of the linac, $\Phi_{\mathrm{E}}(E)_{S}$, and those due to room-return, $\Phi_{\mathrm{E}}(E)_{\mathrm{rr}}$. The neutron fluence at $r \mathrm{~cm}$ from the target, $\phi(r)$, can be calculated by Eq. (1):

$\phi(r)=\int_{\forall E} \Phi_{E}(r, E) d E$ 
The, $\phi(r)$, depends upon the neutron source strength, $Q$, the surface area of the treatment hall inner walls, $S$, and the distance between the linac's head center and the point of interest, $r$, as is shown in Eq. (2):

$\phi(r, S, Q)=Q\left[\frac{\alpha}{4 \pi r^{2}}+5.40 \frac{\alpha}{S}+\frac{c(E)}{S}\right]$

In this equation $\alpha$ is a neutron transmission factor being 1 if the head is mainly lead and 0.85 if the head is mainly tungsten; the $c$ $(E)$ is a constant whose value depends upon the neutron energy being larger for thermal neutrons and lower for neutrons between 1 and $2 \mathrm{MeV}$; however an average value of 5.60 has been proposed for the $c(E)$ (Vega-Carrillo et al., 2007).

Photoneutrons induce activation in the linac components, the walls of the treatment hall, and the patient. Activation is mainly produced by thermal neutrons whose intensity is constant in the treatment hall, due to room return. The induced activity depends upon the neutron energy, the irradiation time, and the type and abundance of nuclei (Konefal et al., 2008; Kafala and Macmahon, 2007), and it has been used to estimate the thermal and resonance neutrons in linacs (Konefal et al., 2012).

The major activation occurs in the collimation system, the stainless steel elements like $\mathrm{Mn}, \mathrm{Ni}$ and $\mathrm{Co}$, and the $\mathrm{Al}$ that reaches the saturation activity due to its short half-life (Polaczek-Grelik et al., 2012). When the induced radioisotopes decay emitting gamma-rays, photons become a radiation protection issue for the facility, including the linac's personal, medical staff and the patient (Janiszewska et al., 2014).

In the bunker the largest component is the concrete, thus the objective of this work was to identify the radioisotopes that are produced in Portland cement samples located in one of the primary barriers when the linac delivers a dose in a phantom.

\section{Materials and methods}

When the activation products decay by $\gamma$-ray emission, the photon energy is used to identify the radionuclide, while the amount of photons is proportional to the mass of the induced radioisotope. This work was carried out at the Tepic's Center of Cancerology located in the state of Nayarit in Mexico where there is a Varian 15 MV linac (Benites-Rengifo et al., 2014).

In order to determine the induced radioisotopes, three cylindrical cement samples $(2.53 \pm 0.01 \mathrm{~cm}$-diameter, $1.06 \pm 0.04 \mathrm{~cm}-$ length) were made. The cement paste was prepared by mixing water and commercial Portland cement using 0.45 water-to-cement ratio. Final samples have a density of $2.1 \pm 0.1 \mathrm{~g} / \mathrm{cm}^{3}$.

Induced radioisotopes in the cement samples were measured with a gamma-ray spectrometer with a $7.62 \mathrm{~cm}-$ diameter $\times 7.62 \mathrm{~cm}$-length $\mathrm{NaI}(\mathrm{Tl})$ scintillator. The spectrometer was calibrated, in energy and efficiency, using ${ }^{60} \mathrm{Co},{ }^{137} \mathrm{Cs}$ and ${ }^{22} \mathrm{Na}$ calibration sources. The sources are from a gamma reference disk source set from Du Pont Pharma having an uncertainty $\leq 3 \%$ in the activity that is traceable to the National Institute of Standards and Technology. Calibration sources are point-like type where the radioisotope is deposited and sealed in the center of a plastic disk $(2.54 \mathrm{~cm}$ in diameter and $0.32 \mathrm{~cm}$ thick). During calibration the source center was located $2.06 \mathrm{~cm}$ above the detector flat-area surface, using a hollow thin-wall $(0.08 \mathrm{~mm})$ polyethylene cylinder $(1.90 \mathrm{~cm}$ height $)$. This piece was also used during the cement samples measurements.

Due to the difference between the point-like sources used for calibration and the cement samples, corrections were carried out including solid angle (Vega-Carrillo 1996, 2005), attenuation, scattering, and photon interactions in the detector. A detailed
Table 1

Cement Portland composition.

\begin{tabular}{ll}
\hline Element & Weight fraction $[\mathbf{o} / \mathbf{w}]$ \\
\hline $\mathrm{H}$ & 0.010000 \\
$\mathrm{C}$ & 0.001000 \\
$\mathrm{O}$ & 0.529107 \\
$\mathrm{Na}$ & 0.016000 \\
$\mathrm{Mg}$ & 0.002000 \\
$\mathrm{Al}$ & 0.033872 \\
$\mathrm{Si}$ & 0.337021 \\
$\mathrm{~K}$ & 0.013000 \\
$\mathrm{Ca}$ & 0.044000 \\
$\mathrm{Fe}$ & 0.014000 \\
\hline
\end{tabular}

Monte Carlo model of the scintillator was built using the MCNP 5 code (X-5 Monte Carlo Team, 2003). In the model the polyethylene support and the cement cylinder were included. The elemental composition used to model the cement is shown in table 1 (McConn et al., 2011). In the calculations the actual density of cement samples was used $\left(2.0 \mathrm{~g} / \mathrm{cm}^{3}\right)$.

Calculations were carried out using monoenergetic photon sources $(0.05-3 \mathrm{MeV})$ distributed in cement cylinders and as point-like sources. The tally f8 was used to estimate the pulse height spectra and the net area under the photopeak was used to estimate the efficiency.

The Monte Carlo efficiencies were used to calculate the efficiency for the cement cylinders measurements using the efficiency measured with the point-like sources as is shown in Eq. (3):

$\varepsilon_{\mathrm{CC}}(E)=\varepsilon_{\mathrm{CC}, \mathrm{MC}}(E) \frac{\varepsilon_{\mathrm{P}, \operatorname{Exp}}(E)}{\varepsilon_{\mathrm{P}, \mathrm{MC}}(E)}$

Here, $\varepsilon_{\mathrm{CC}}(E)$ is the efficiency of cement Portland cylinder, $\varepsilon_{\mathrm{CC}, \mathrm{MC}}(E)$ is the efficiency of cement Portland cylinder calculated with Monte Carlo, $\varepsilon_{\text {P,Exp }}(E)$ is the experimental efficiency obtained with the calibrated point-like sources, and $\varepsilon_{\mathrm{P}, \mathrm{MC}}(E)$ is the efficiency of the point-like sources calculated with Monte Carlo. The uncertainties of Monte Carlo calculations are $0.1 \%$ while the experimental is $4 \%$. These efficiencies are shown in fig. 1 .

The detector was installed on a Styrofoam base and the spectrometer was set in a hall located near the treatment room, as is shown in Fig. 2.

The pulse height spectrum due to background was measured during $24 \mathrm{~h}$ and it was used to make corrections in the measured pulse height spectra.

In the experiments the accelerator was set to deliver 1200 monitor units (MU) at a rate of $300 \mathrm{MU} / \mathrm{min}$ ( $100 \mathrm{MU} / \mathrm{cGy}$ ) using $15 \mathrm{MeV}$ photon beam. The irradiation area was $20 \mathrm{~cm} \times 20 \mathrm{~cm}$ in

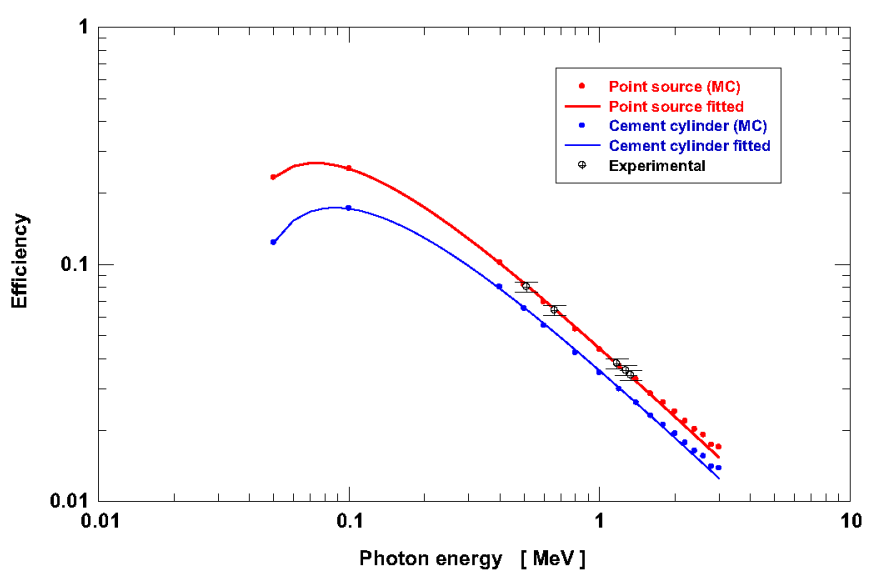

Fig. 1. Experimental and calculated efficiencies. 


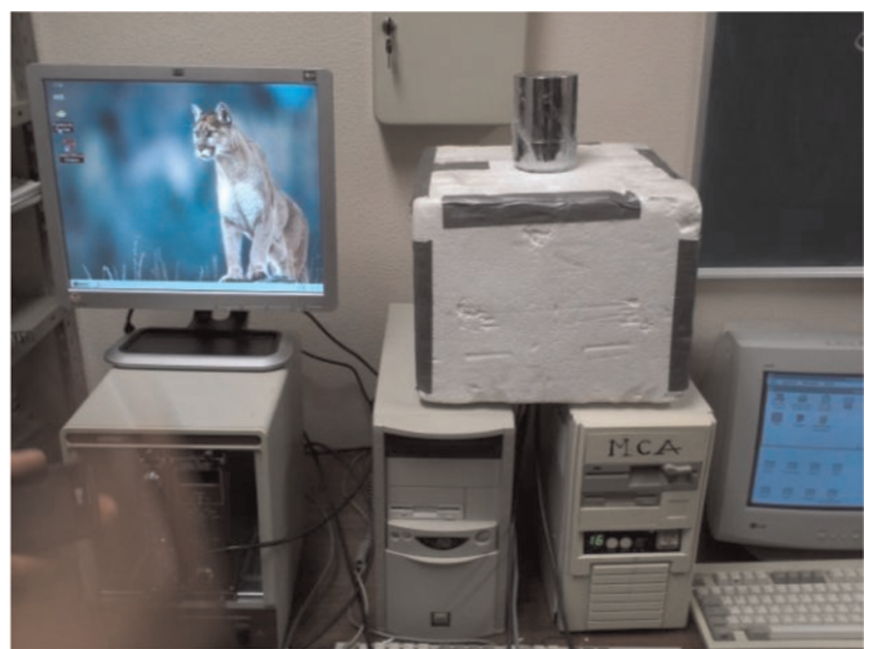

Fig. 2. Gamma-ray spectrometer with a $7.62 \emptyset \times 7.62 \mathrm{~cm}^{2} \mathrm{Nal}(\mathrm{Tl})$ detector.

the isocenter (IC). The dose was delivered on a solid water phantom set on the couch, while the head was above the phantom. The IC was allocated $100 \mathrm{~cm}$ from the linac's target, to $5 \mathrm{~cm}$-depth of a $30 \mathrm{~cm} \times 30 \mathrm{~cm} \times 15 \mathrm{~cm}$ solid water phantom. After the irradiation the cement samples decay time was measured to make the proper corrections.

Each cement sample was irradiated independently using the same linac's irradiation features. The samples were localized on a primary concrete barrier, to $3 \mathrm{~m}$ from the linac's target and to $90^{\circ}$ from the beam direction, as is shown in Fig. 3. In this position cement samples were exposed to scattered and room return neutrons.

Using the MCNP5 code a model of the bunker, the solid water phantom and the linac head was built (Benites-Rengifo et al., 2014) and the neutron spectrum reaching the wall where the cement samples were located was calculated. This neutron spectrum is shown in Fig. 4.

After the irradiation, cement samples were measured for 15 min (live time) and the pulse height spectra were obtained. The net areas under the photopeaks $(N)$ were used to calculate the induced activity $(A)$ using Eq. (4) as follow:

$A=\frac{N e^{\lambda t c}}{\sec p_{r} t}$

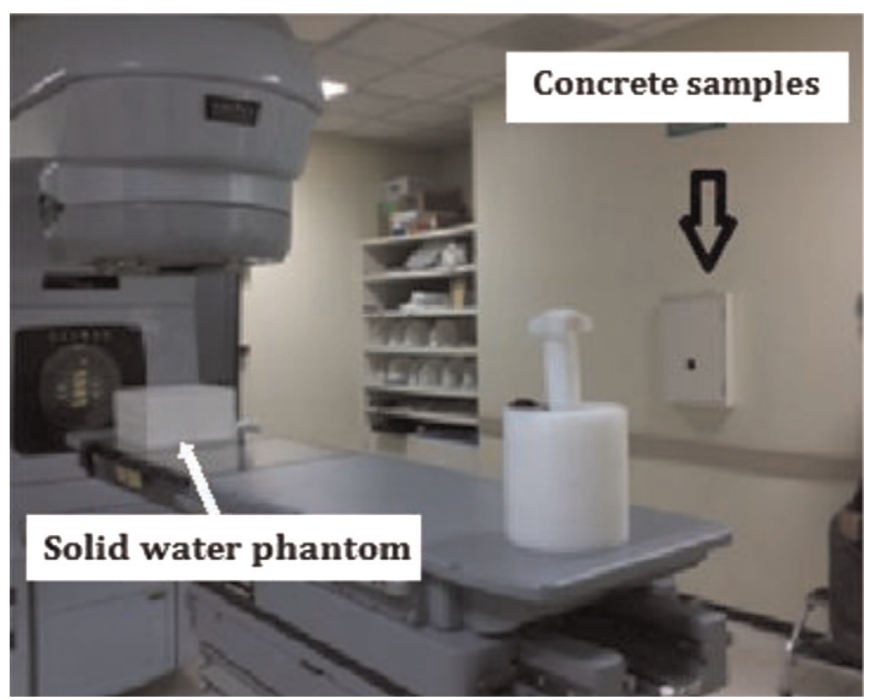

Fig. 3. Site where the concrete samples were located in the treatment room.

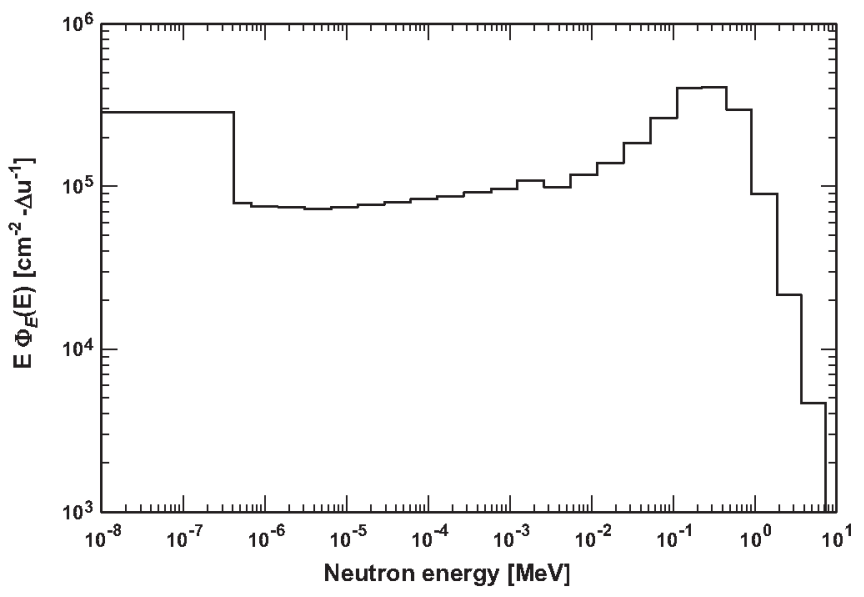

Fig. 4. Neutron spectrum that reach the cement samples.

In this equation $t_{\mathrm{c}}$ is the cooling time (time delay between time of beam-off and the start of pulse-height spectrum acquisition), $p_{\gamma}$ is the gamma-ray emission probability of the observed photopeak, $t$ is the live measurement time, and $\varepsilon_{\mathrm{CC}}$ is the efficiency calculated from Eq. (3).

In some treatments there is a requirement to shape to a dose profile and a wedge is eventually used. The wedge is an alloy of Fe, $\mathrm{Si}, \mathrm{Mn}, \mathrm{Cr}$ and $\mathrm{Ni}$ (Guo and Ziemer, 2004) and photoneutrons could induce activation as well. Once the wedge is used is withdrawn from the linac head keeping the wedge near or in contact with the body of the linac staff.

In order to determine the induced activity in the wedge, in the last experiment a wedge was located on the linac head (below the multileaf collimator). The linac was operated with the same features used with the concrete samples. When the linac was off, the $\gamma$-ray spectrometer was moved into the treatment hall and the detector was fixed on the top of the wedge as is shown in Fig. 5.

\section{Results}

Cement Portland samples were sited inside the bunker of a $15 \mathrm{MeV}$ linac. The photoneutrons produced by the linac, induce

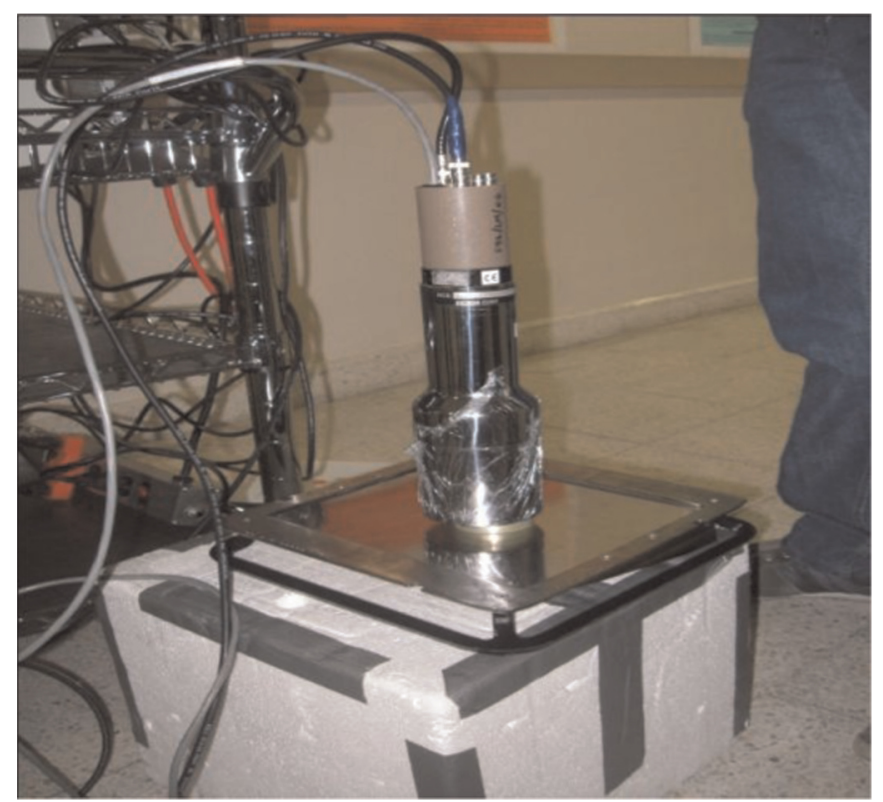

Fig. 5. Spectroscopy system to measure a wedge. 


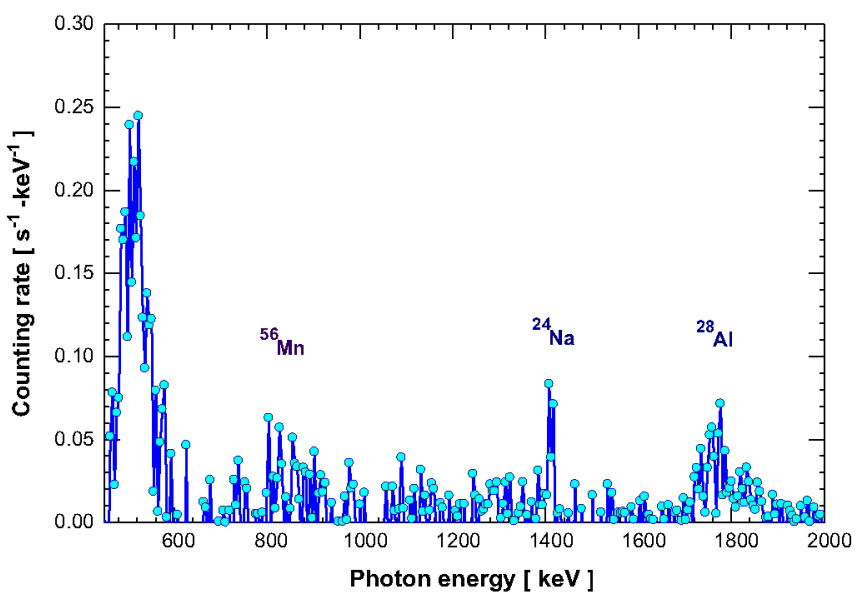

Fig. 6. Induced activity in concrete sample $\mathrm{N}^{\circ} 1$.

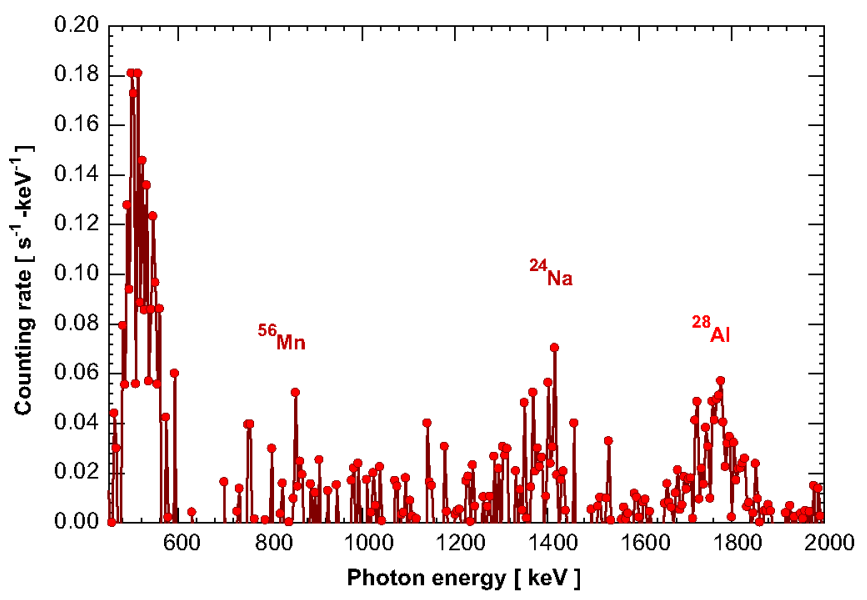

Fig. 7. Induced activity in concrete sample $\mathrm{N}^{\circ} 2$.

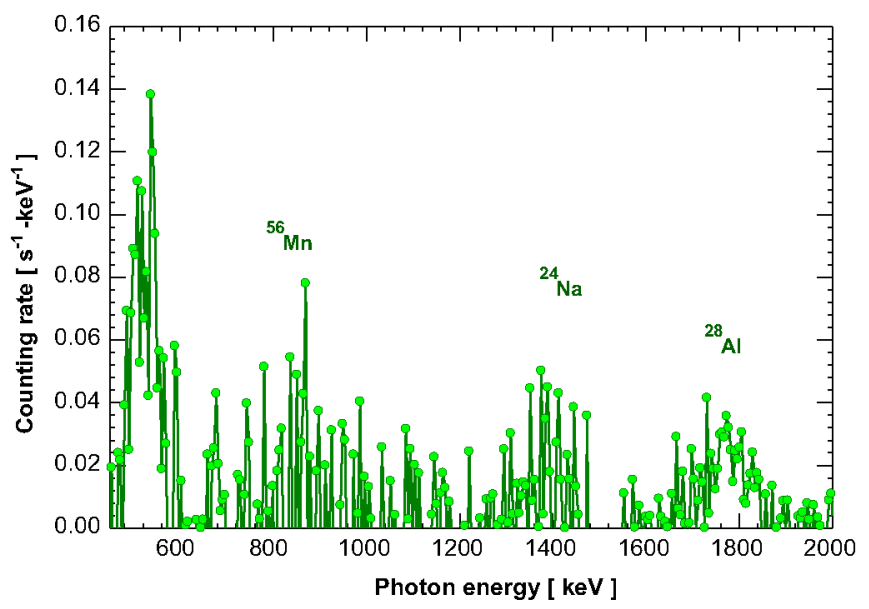

Fig. 8. Induced activity in concrete sample $\mathrm{N}^{\circ} 3$.

the activation of the samples. In Figs. $6-8$ the pulse height spectra of the cement samples are shown.

In the spectra $846 \mathrm{keV}, 1368 \mathrm{keV}$ and $1778 \mathrm{keV}$ photopeaks are noticed probably produced by ${ }^{56} \mathrm{Mn},{ }^{24} \mathrm{Na}$ and ${ }^{28} \mathrm{Al}$ respectively. The induction of these radioisotopes has been reported in medical linacs as well (Konefal et al., 2008, 2012).

The features of the induced radioisotopes in the concrete are shown in the Table 2.

Using the net counts under the photopeaks measured in the
Table 2

Features of the radioisotopes induced in the concrete samples.

\begin{tabular}{llcl}
\hline Element & Nuclide & Gamma lines measured [keV] & Half life \\
\hline $\mathrm{Al}$ & ${ }^{28} \mathrm{Al}$ & 1778.8 & $2.24 \mathrm{~m}$ \\
$\mathrm{Na}$ & ${ }^{24} \mathrm{Na}$ & 1368.6 & $14.96 \mathrm{~h}$ \\
$\mathrm{Mn}$ & ${ }^{56} \mathrm{Mn}$ & 846.8 & $2.58 \mathrm{~h}$ \\
\hline
\end{tabular}

cement samples the specific activity in concrete was calculated whose values are shown in Table 3.

The mean values of the induced specific activities in the three concrete samples are: $0.1543 \pm 0.0199 \mathrm{~Bq} / \mathrm{g}$ due to ${ }^{56} \mathrm{Mn}$, $0.5021 \pm 0.1893 \mathrm{~Bq} / \mathrm{g}$ due to ${ }^{24} \mathrm{Na}$ and $1.977 \pm 0.2804 \mathrm{~Bq} / \mathrm{g}$ due to ${ }^{28} \mathrm{Al}$. It has been reported the induction of these radionuclides in the head casting of a linac (Polaczek-Grelik et al., 2012).

Fig. 8 shows the pulse height spectrum of the radioisotopes induced in the wedge, where the main peaks were 846, 1811 and $2112 \mathrm{keV}$ that are emitted by ${ }^{56} \mathrm{Mn}$. This radioisotope was also reported in wedges (Guo and Ziemer, 2004; Konefal et al., 2008). After a treatment the wedge is withdrawn by the accelerator staff, due to its shape and weight the wedge is carried attached to the chest of the auxiliary or medical staff exposing them to photons.

The geometry used in the induced activity in the wedge was different to the geometry used to determine the spectrometer efficiency therefore; in this case, the specific activity was not determined (Fig. 9).

\section{Discussion}

Photoneutrons produced by a 15 MV linac will activate the accelerator, the treatment aids like the wedge and the surrounding environment like the air and the cement in the concrete. The radiation doses from these activation products are non-insignificant (Guo and Ziemer, 2004).

Nevertheless, the dose due the induced activity is not considered in radiological protection program in the facility.

The neutron spectrum reaching the primary barrier looks alike the neutron spectrum measured near the inner wall of a bunker with a cyclotron for positron emission tomography (Vega-Carrillo, 2001). According to Fujibuchi et al. (2015) and Martínez-Serrano and Diez de los Ríos (2010) the induced activity in the concrete walls is approximately constant in the first $10 \mathrm{~cm}$ deep in the walls. Assuming that photoneutrons in the linac induce activation to $5 \mathrm{~cm}$ depth in the concrete walls, the radiotherapy room can be estimated as a gamma-ray shell. Some of the decay photons can reach the patient body during treatment. Also, the personal that go into the room to assist the patient when the accelerator goes off, will receive a dose.

In the cement, the induced radioisotopes were ${ }^{28} \mathrm{Al},{ }^{24} \mathrm{Na}$ and ${ }^{56} \mathrm{Mn}$ whose half-life varies from few minutes up to several hours.

Table 3

Specific activities of the induced radioisotopes in the concrete samples.

\begin{tabular}{llc}
\hline Concrete sample & Radioisotope & Specific activity [Bq/g] \\
\hline 1 & ${ }^{56} \mathrm{Mn}$ & $0.1684 \pm 0.0151$ \\
& ${ }^{24} \mathrm{Na}$ & $0.2981 \pm 0.0270$ \\
& ${ }^{28} \mathrm{Al}$ & $1.8674 \pm 0.1680$ \\
& ${ }^{56} \mathrm{Mn}$ & $0.1314 \pm 0.0118$ \\
2 & ${ }^{24} \mathrm{Na}$ & $0.6720 \pm 0.0604$ \\
& ${ }^{28} \mathrm{Al}$ & $2.2951 \pm 0.2064$ \\
& ${ }^{56} \mathrm{Mn}$ & $0.1630 \pm 0.0201$ \\
3 & ${ }^{24} \mathrm{Na}$ & $0.5361 \pm 0.0484$ \\
& ${ }^{28} \mathrm{Al}$ & $1.7671 \pm 0.1591$ \\
\hline
\end{tabular}




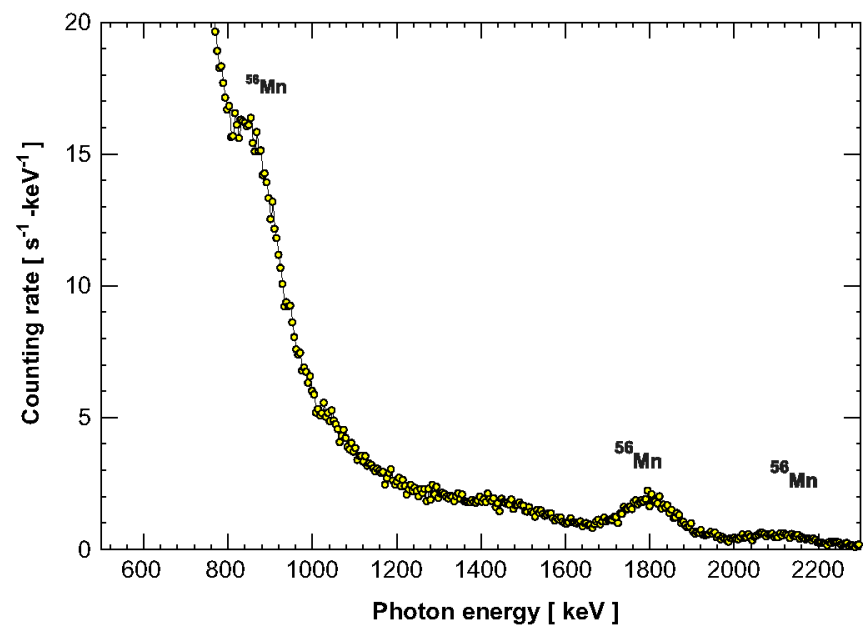

Fig. 9. Pulse height spectrum of the wedge.

In order to improve the ALARA criteria is important that the linac staff be aware of what elements are inside of the room which are easy to be activated.

In Table 1 the main components of Portland cement do not include $\mathrm{Mn}$, however during the preparation of Portland cement standards the National Bureau of Standards reported the presence of Mn (Kirby and Kanare, 1998).

The induced radioisotopes in the cement were identified however, due to the $\mathrm{NaI}(\mathrm{Tl})$ poor resolution, very short-lived or pure beta-emitting nuclides were not identified (Fischer et al., 2008).

In the wedge ${ }^{56} \mathrm{Mn}$ was identified. The presence of $\mathrm{Mn}$ is probably due to the steel (Konefal et al., 2008). The specific activity was not estimated due the wedge size. In the pulse height spectrum the three peaks related to the ${ }^{56} \mathrm{Mn}$ decay are shown. The ${ }^{56} \mathrm{Mn}$ activation and decay is given in Eq. (5):

$$
\begin{aligned}
& { }_{0}^{1} \mathrm{n}+{ }_{25}^{55} \mathrm{Mn}(100 \%) \Rightarrow \gamma+{ }_{25}^{56} \mathrm{Mn} \underset{\mathrm{T}_{1 / 2}=2.58 h}{\rightarrow}{ }_{26}^{56} \mathrm{Fe}^{*} \\
& +\beta^{-} \underset{T_{1 / 2} \leq 6 \mathrm{ps}}{\rightarrow}{ }_{26}^{56} \mathrm{Fe}+\gamma\left\{\begin{array}{c}
846.77 \mathrm{keV}(100 \%) \\
1810.77 \mathrm{keV}(27.2 \%) \\
2113.12 \mathrm{keV}(14.3 \%)
\end{array}\right.
\end{aligned}
$$

The wedge pulse height spectrum reported by Konefal et al. (2008), that was measured with an $\mathrm{Ge}(\mathrm{Li})$ detector, shows the 846.77 and $1810.77 \mathrm{keV}$ photons due to ${ }^{56} \mathrm{Mn}$; also, they reported the $899.15,911.78 \mathrm{keV}$ due to ${ }^{204 \mathrm{mPb}}$ and $1778.96 \mathrm{keV}$ due to ${ }^{28} \mathrm{Si}^{*}$. The energy of these photons are close the photons emitted by ${ }^{56} \mathrm{Mn}$, but due the low resolution of $\mathrm{NaI}(\mathrm{Tl})$ detector they appear in the photopeaks of ${ }^{56} \mathrm{Mn}$.

\section{Conclusions}

Induced radioisotopes, in cement samples and a wedge, have been identified during the operation of a $15 \mathrm{MV}$ linac. The radioisotopes are activated by the photoneutrons produced during the linac operation.

The primary and secondary barriers in the treatment hall are several tons of concrete that are activated during a patient treatment, behaving as a $4 \pi$ source that deliver a dose in the hall lasting up to few hours after the treatment.

In the cement samples the induced radioisotopes were ${ }^{56} \mathrm{Mn}$, ${ }^{24} \mathrm{Na}$ and ${ }^{28} \mathrm{Al}$ that during their decay produce 846.8, 1368.6 and $1778.8 \mathrm{keV}$ photons respectively with a half life that goes from few minutes up to several hours.
The average specific activity of the three cement samples used is $0.1543,0.5021$ and $1.977 \mathrm{~Bq}$ per gram of cement due to ${ }^{56} \mathrm{Mn}$, ${ }^{24} \mathrm{Na}$ and ${ }^{28} \mathrm{Al}$, respectively.

In the wedge the induction of ${ }^{56} \mathrm{Mn}$ was identified.

\section{Acknowledgments}

The second (HALM) and third author (ERP), thanks to the Consejo Nacional de Ciencia y Tecnología (CONACyT, Mexico) for the scholarship during the postgraduate studies. This work is part of the project MONITOR 2, partially supported by the Consejo Zacatecano de Ciencia Tecnología e Innovación (COZCyT).

\section{References}

Agosteo, S., 2010. Overview of novel techniques for radiation protection and dosimetry. Radiat. Meas. $45,1171-1177$.

Agosteo, S., Birattari, C., Caravaggio, Silari, M., Tosi, G., 1998. Secondary neutron and photon dose in proton therapy. Radiother. Oncol. 48, 293-305.

Amaldi, U., Braccini, S., 2011. Present challenges in hadrontherapy techniques. Eur. Phys. J. Plus 126, 70-84.

Barquero, R., Mendez, R., Vega-Carrillo, H.R., Iñiguez, M.P., Edwards, T.M., 2005. Neutron spectra and dosimetric features around a $18 \mathrm{MV}$ medical linear accelerator. Health Phys. 88, 49-59.

Benites-Rengifo, J.L., Vega-Carrillo, H.R., Velazquez-Fernandez, J., 2014. Photoneutron spectrum measured with a Bonner sphere spectrometer in planetary method mode. Appl. Radiat. Isot. 83, 256-259.

Fischer, H.W., Tabot, B., Poppe, B., 2008. Comparison of activation products and induced dose rates in different high-energy medical linear accelerators. Health Phys. 94, 272-278.

Fujibuchi, T., Nohtomi, A., Baba, S., Sasaki, M., Komiya, I., Umedzu, Y., Honda, H., 2015. Distribution of residual long-lived radioactivity in the inner concrete walls of a compact medical cyclotron vault room. Ann. Nucl. Med. 29, 84-90.

Guo, S., Ziemer, P.L., 2004. Health physics aspects of neutron activated components in a linear accelerator. Health Phys. 86 (Supplement 2), S94-S102.

Janiszewska, M., Polaczek-Grelik, K., Raczkowski, M., Szafron, B., Konefal, A., Zipper, W., 2014. Secondary radiation dose during high-energy total body irradiation. Strahlenther. Onkol. 190, 459-466.

Kafala, S.I., Macmahon, T.D., 2007. Comparison of neutron activation analysis methods. J. Radioanal. Nucl. Chem. 271, 507-516.

Kirby, R.K., Kanare, H.M., 1998. Portland Cement Chemical Composition Standards (Blending, Packaging and Testing). 260. National Bureau of Standards Publication, Gaithersburg, MD, 110.

Konefal, A., Polaczek-Grelik, K., Zipper, W., 2008. Undesirable nuclear reactions and induced radioactivity as a result of the use of the high-energy therapeutic beams generated by medical linacs. Radiat. Prot. Dosim. 128, 133-145.

Konefal, A., Orlef, A., Dybek, M., Maniakowski, Z., Polaczek-Grelik, K., Zipper, W. 2008. Correlation between radioactivity induced inside the treatment room and the underisable thermal/resonance neutron radiation produced by linac. Phys. Med. 24, 212-218.

Konefal, A., Orlef, A., Laciak, M., Ciba, A., Szewczuk, M., 2012. Thermal and resonance neutrons generated by various electron and X-ray therapeutic beams from medical linacs installed in polish oncological centers. Rep. Pract. Oncol. Radiother. 17, 339-346.

Kry, S.F., Titt, U., Followill, D., Ponisch, F., Vassiliev, O.N., White, R.A., Stovall, M., Salehpour, M., 2007. A Monte Carlo model for out-of-field dose calculation from high-energy photon therapy. Med. Phys. 34, 3489-3499.

Lenox, A.J., 2001. Accelerators for cancer therapy. Radiat. Phys. Chem. 61, 223-226.

Martínez-Serrano, J.J., Díez de los Ríos, A., 2010. Prediction of neutron induced radioactivity in the concrete walls of a PET cyclotron vault room with MCNPX. Med. Phys. 37, 6015-6021.

McConn Jr, R.J., Gesh, C.J., Pagh, R.T., Rucker, R.A., WilliamsIII, R.G., R.A., 2011. Compendium of material composition data for radiation transport modeling. Pacific Northwest National Laboratory, PNNL-15870 Rev. 1, Richland, Washington.

Ognaro, C., Zanini, A., Nastasi, U., Ródenas, J., Ottaviano, G., Manfredotti, C., 2000 Analysis of photoneutron spectra produced in medical accelerators. Med. Phys. Biol. 45, 55-61.

Polaczek-Grelik, K., Karaczyn, B., Konefal, A., 2012. Nuclear reactions in linear medical accelerators and their exposure consequences. Appl. Radiat. Isot. 70, 2332-2339.

Price, K.W., Nath, R., Holeman, G.R., 1978. Fast and thermal neutron profiles for a 25-MV X-ray beam. Med. Phys. 5, 285-289.

Stathakis, S., Li, J., Ma, Ch.C.M., 2007. Monte Carlo determination of radiation-induced cancer risk for prostate patients undergoing intensity-modulated radiation therapy. J. Appl. Clin. Med. Phys. 8, 14-27.

Suit, H., Goldberg, S., Niemierko, A., Ancukiewicz, M., Hall, E., Goitein, M., Wong, W., Paganetti, H., 2007. Secondary carcinogenesis in patients treated with 
Radiation: a review of data on radiation-induced cancers in human, non-human primate, canine and rodent subjects. Radiat. Res. 167, 12-42.

Travis, L.B., Ng, A.K., Allan, J.M., Pui, C.H., Kennedy, A.R., Xu, X.G., Purdy, J.A., Applegate, K., Yahalom, J., Constine, L.S., Gilbert, E.S., Boice Jr., J.D., 2012. Second malignant neoplasms and cardiovascular disease following radiotherapy. J. Natl. Cancer Inst. 104, 357-370.

Vega-Carrillo, H.R., 1996. Geometry efficiency for a parallel disk source and detector. Nucl. Instrum. Methods Phys. Res. A 371, 535-537.

Vega-Carrillo, H.R., 2001. Neutron energy spectra inside a PET cyclotron vault room. Nucl. Instrum. Methods Phys. Res. A 463, 375-386.

Vega-Carrillo, H.R., 2005. Erratum to geometrical efficiency for a parallel disk source and detector. Nucl. Instrum. Methods Phys. Res. A 583, 814

Vega-Carrillo, H.R., Manzanares, E., Iñiguez, M.P., Gallego, E., Lorente, A., 2007.
Study of room-return neutrons. Radiat. Meas. 42, 413-419.

Vega-Carrillo, H.R., Hernández-Almaraz, B., Hernández-Dávila, V.M., Ortíz-Hernández, A., 2010. Neutron spectrum and doses in a 18 MV LINAC. J. Radioanal. Nucl. Chem. 283, 261-265.

X-5 Monte Carlo Team, 2003. MCNP-A General Monte Carlo N-Particle TransportCode, Version 5. Los Alamos National Laboratory, Report LA-CP-03-0245, New Mexico.

Zabihzadeh, M., Reza, M., Allahverdi, M., Mesbahi, A., Rabee, S., Shahriari, M., 2009 Monte Carlo estimation of photoneutrons contamination from high-energy $\mathrm{X}$-ray medical accelerators in treatments room and maze: a simplified model. Radiat. Prot. Dosim. 135, 21-32. 